\title{
ACOSO LABORAL EN COSTA RICA
}

ELIZARDA VARGAS MORÚA

Escuela de Ciencias de la Administración Universidad Estatal a Distancia, Costa Rica

evargasm@uned.ac.cr

\section{RESUMEN}

Este artículo constituye un análisis descriptivo de las resoluciones judiciales de Costa Rica respecto al acoso laboral. De acuerdo con el Sistema Costarricense de Información Jurídica son 23 resoluciones clasificadas bajo el tema de "acoso laboral" relativas a procesos iniciados desde el año 1998 al presente. También se analiza la información suministrada por el Ministerio de Trabajo y Seguridad Social de las denuncias que se tramitaron por la vía administrativa. Aunque el ordenamiento costarricense aún no ha regulado especificamente el acoso laboral, ello no implica que el trabajador no tenga derecho a su reclamo y su indemnización. La falta de pruebas ha sido una limitante para las víctimas del acoso laboral, pero en aquellos casos en que se ha demostrado dicha situación, las sentencias le han concedido al trabajador la orden de reinstalación en su puesto o bien el pago de preaviso y cesantía, entre otros derechos.

PALABRAS CLAVE: ACOSO LABORAL, MOBBING, HOSTIGAMIENTO LABORAL, PERSECUCIÓN LABORAL, SENTENCIAS LABORALES.

\section{ABSTRACT}

This article constitutes a descriptive analysis of Costa Rica's legal rulings regarding workplace harassment. It considers the total sentences classified under the matter of "workplace harassment" in the Costa Rican Juridical Information System, a total of twenty-three legal rulings relating to processes initiated from 1998 to the present. It also analyzes the information provided by the Ministry of Labor and Social Security relating to formal complaints received by administrative channels. Although our system has not regulated labor harassment specifically, it doesn't imply that employees don't have the right to claim and received compensation. The lack of evidence has been a limiting factor for the victims of mobbing, but in those cases where this situation has been shown, the judgments have granted the employee the order of reinstatement in his position or payment of notice and severance pay, among other rights.

KEYWORDS: MOBBING, LABOR HARASSMENT, LABOR RELATED PERSECUTION.

\section{INTRODUCCIÓN}

El comportamiento que adopta una persona en su ámbito laboral, para perjudicar a un empleado o grupo de empleados, con la intención incluso de que esta persona renuncie a su empleo, se conoce con el nombre de acoso laboral u hostigamiento laboral.

Mediante este artículo se realizará un análisis descriptivo del acoso laboral en el contexto costarricense, tanto en el ámbito administrativo como judicial. En cuanto a la vía administrativa se contemplará la información suministrada por el Ministerio de Trabajo y Seguridad Social respecto a las denuncias que se tramitaron por esa vía en el periodo 2007-2009. Si bien los funcionarios públicos además de las dos vías ya indicadas podrían 
recurrir a la Defensoría de los Habitantes, estos casos no fueron contemplados. Para la información del sistema judicial, se recurrió al Sistema Costarricense de Información Jurídica donde bajo el tema "acoso laboral" se obtuvieron 23 sentencias hasta mayo del año 2011. Estas resoluciones contemplan toda la información de los casos clasificados sobre acoso laboral y contienen denuncias del año 1998 en adelante.

Mediante el presente estudio se pretende responder a las siguientes preguntas de investigación: ¿qué elementos consideran los órganos jurisdiccionales para determinar cuándo ha habido acoso laboral?, ¿cuáles son las principales limitaciones que presentan las víctimas del acoso laboral al presentar la denuncia?, ¿en qué situaciones los tribunales han considerado que sí ha habido acoso laboral y en cuáles no?, ¿cuál es la normativa aplicable en Costa Rica?, Estas y otras temáticas respecto al acoso laboral se contemplarán en el presente trabajo.

\section{MARCO TEÓRICO}

Fue a partir de la década de los ochenta que el doctor Heinz Leymann, psicólogo, pedagogo y psiquiatra nacionalizado sueco, empezó a denominar, estudiar y sistematizar el estudio del fenómeno denominado "mobbing" vocablo del inglés "to mob" que significa acción de agredir, acosar, atacar, maltratar, en masa o en grupo a alguien (Romero, 2006).

Estudios posteriores, como los publicados en el año 1998 por la Organización Internacional del Trabajo, indican que el acoso laboral genera problemas en las relaciones interpersonales, en la organización y en el ambiente general del trabajo. Puede reducir la eficiencia y la productividad laboral, el deterioro del producto laboral, la pérdida de la imagen corporativa o la reducción del número de clientes.
En la literatura española se usa indistintamente el término mobbing o acoso laboral: "el mobbing o acoso laboral causa enormes sufrimientos a las personas que lo padecen y merma la competitividad potencial de las empresas" (Piñuel, 2001).

La doctrina clasifica en cuatro categorías posibles de acoso u hostigamiento: ascendente, descendente y entre iguales. La cuarta categoría sería la que integra a las tres (Pérez 2008).

El acoso descendente lo constituyen aquellas acciones en las que un jefe de manera abusiva, desmesurada y perversa fuerza a un subalterno a dejar el trabajo de manera voluntaria o a solicitar el cambio o la baja laboral, logrando así eliminar al subalterno del lugar de trabajo (Piñuel, 2001). Según señala Pérez (2008) agrega que esta jefatura puede utilizar peones cómplices a su cargo para ejecutar las actividades sin que aparezca él.

En el acoso ascendente, un grupo de subalternos acosa a la jefatura a través de intromisiones en su vida privada, cuestionamientos de su estilo de gestión, el no tener requisitos para el puesto, entre otros.

Cabe destacar que no se denomina acoso, cuando la jefatura está actuando bajo los lineamientos establecidos en la organización y está al amparo de la sana administración y aplicación de la normativa vigente. Normalmente este acoso se da por luchas de poder, posiciones políticas, afinidades subjetivas (Pérez, 2008).

El acoso laboral entre iguales se presenta cuando trabajadores de un mismo nivel que no ostentan un cargo o jefatura formal, como podrían ser coordinadores o mandos medios, sin tener el poder para tomar decisiones, atacan a una víctima con el fin de que se le traslade o despida (Pérez, 2008). 
FIGURA 1

\section{Tipología de acoso laboral}

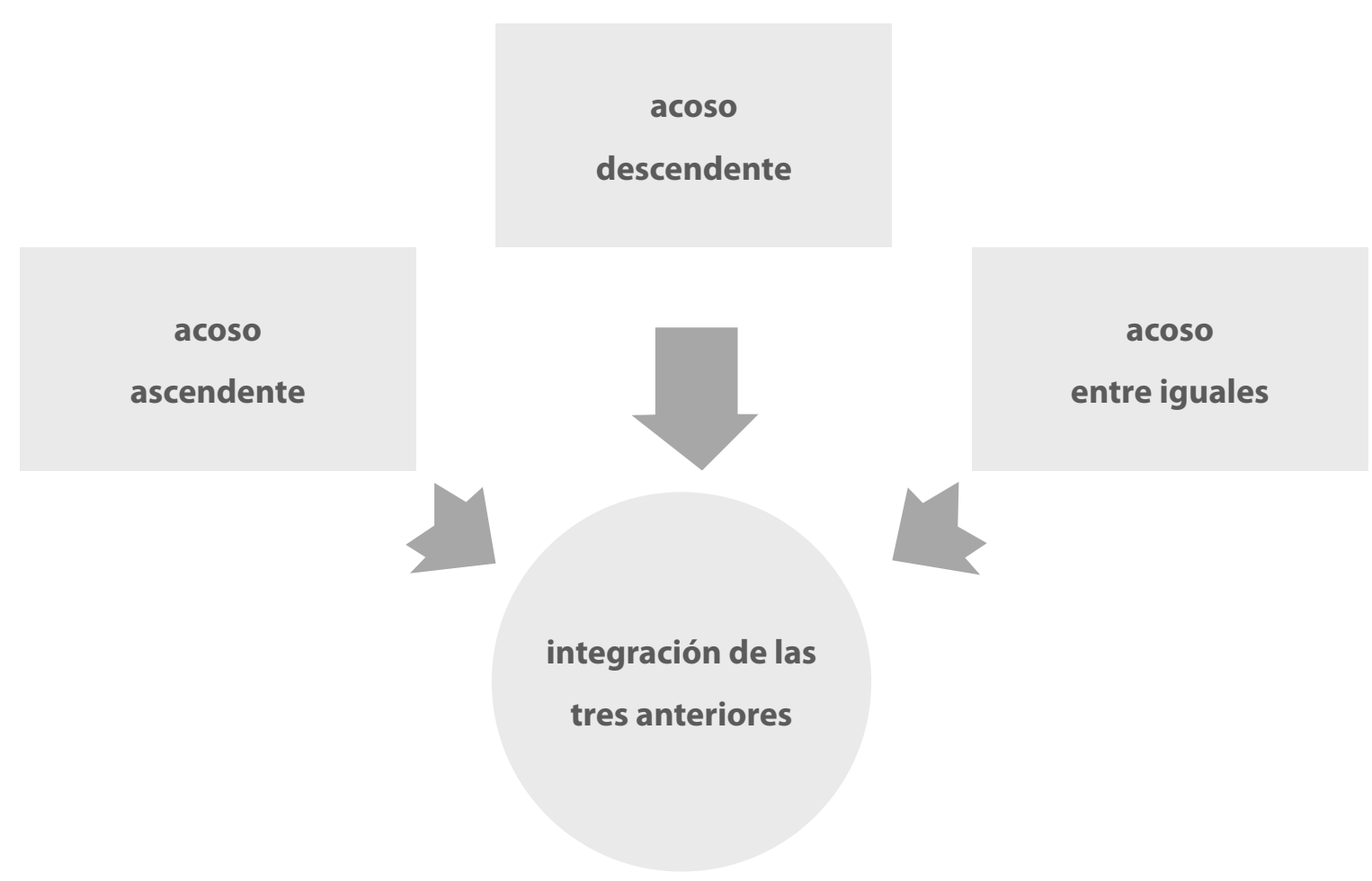

Fuente: Elaboración propia a partir de Pérez (2008).

\section{METODOLOGÍA}

Para llevar a cabo el presente trabajo se obtuvo información por dos vías: Ministerio de Trabajo y todas las resoluciones clasificadas bajo el tema "acoso laboral" existentes en el Sistema Costarricense de Información Judicial, que suman en total 23.

A través de la Dirección Nacional de Inspección de Trabajo, Departamento de Gestión del Ministerio de Trabajo y Seguridad Social se obtuvo información de los trámites de carácter administrativo que realizan las víctimas e información respecto a los denunciantes. La información obtenida en el Ministerio corresponde del año 2007 al 2009 es la más actualizada que se ofrece al momento de la redacción de este artículo. Es importante porque se obtuvieron datos respecto al número de denunciantes, los sectores de donde provenían y la forma como concluyeron los procesos administrativos.

Con respecto a las resoluciones judiciales, estas se obtuvieron en la versión electrónica a través del Sistema Costarricense de Información Jurídica bajo el título de "acoso laboral". Dichas resoluciones fueron emanadas de la Sala Segunda y Sala Constitucional de la Corte Suprema de Justicia, el Tribunal Contencioso Administrativo, Sección IV y Sección VII del Segundo Circuito Judicial de San José y el Tribunal de Trabajo, Sección III del Segundo Circuito Judicial y constituyen la totalidad de las sentencias clasificadas bajo este tópico al momento de la consulta. 
Con base en la información obtenida se procedió a realizar un análisis descriptivo y de esta forma obtener conclusiones generales del abordaje del acoso laboral en Costa Rica hasta mayo del año 2011.

\section{El acoso laboral en el contexto costarricense}

En Costa Rica, las denuncias por acoso laboral se pueden presentar ante el Ministerio de Trabajo y Seguridad Social o bien directamente ante los
Tribunales de Justicia (cabe aclarar que los funcionarios públicos también podrían recurrir ante la Defensoría de los Habitantes). Para el caso que el ofendido recurra ante el Ministerio, se señalará una audiencia entre las partes para intentar lograr un arreglo, si este no se logra, la parte ofendida puede recurrir ante los Órganos Jurisdiccionales. La denuncia de los hechos ante el Ministerio de Trabajo y Seguridad Social (MTSS) es opcional, ya que el afectado (a) puede también acudir directamente ante los Tribunales de Justicia y obviar el paso ante el Ministerio, tal y como se representa en la figura 2:

FIGURA 2

\section{Dos vías para interponer la denuncia por acoso laboral en Costa Rica}

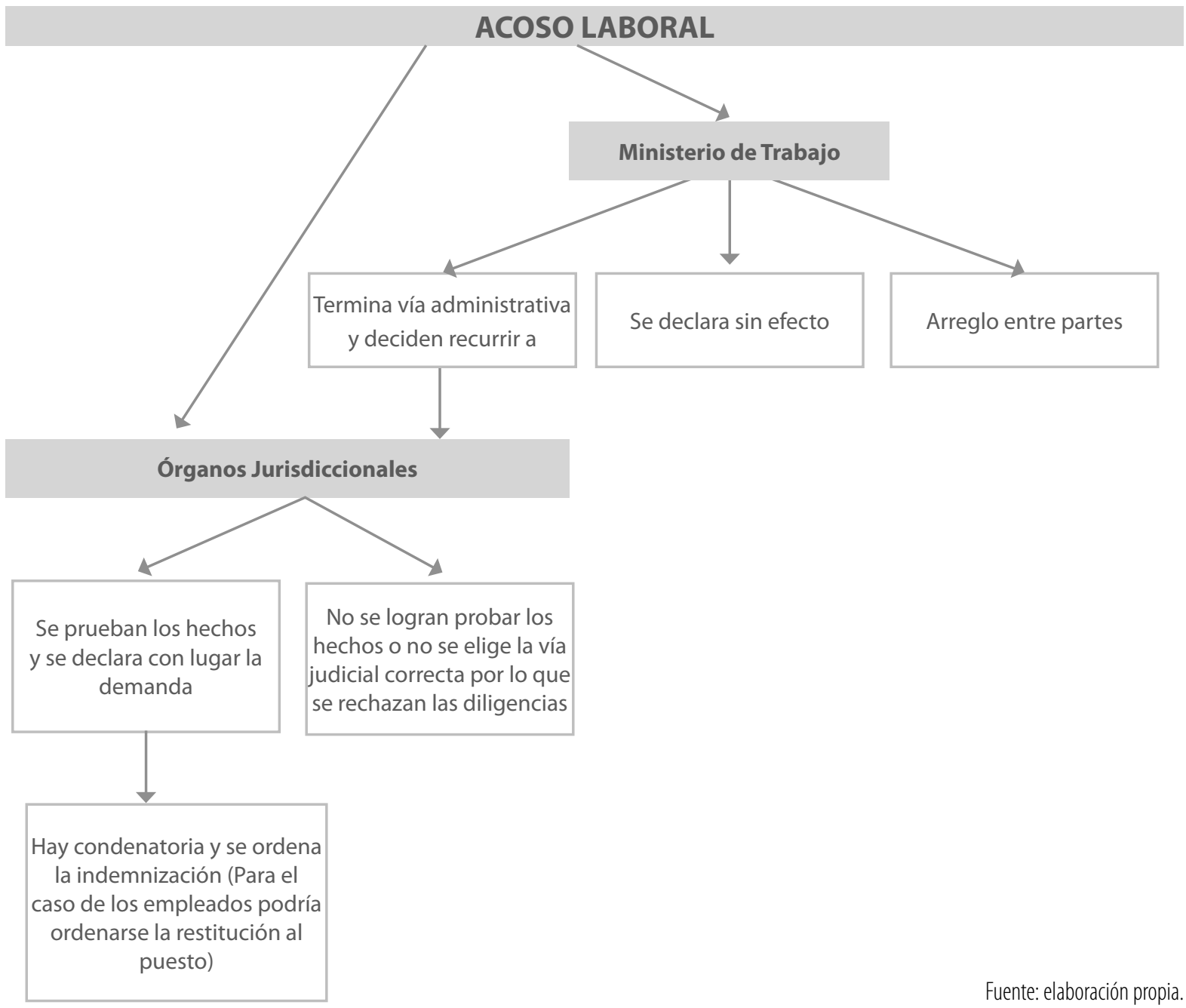


Antes del año 2006, las denuncias por acoso laboral ante el Ministerio de Trabajo y Seguridad Social eran escasas por lo que hasta ese año no hay reportes oficiales. Los primeros registros concretos datan del año 2007 en adelante como se aprecia en la tabla número uno.

TABLA 1

\section{Denuncias por Hostigamiento ante el Ministerio de Trabajo y Seguridad Social Año 2007- 2009}

\begin{tabular}{|c|c|c|}
\hline $\begin{array}{c}\text { Hostigamiento } \\
\text { laboral }\end{array}$ & Absoluto & Variación \% \\
\hline 2007 & 36 & \\
\hline 2008 & 36 & $0,0 \%$ \\
\hline 2009 & 92 & $155,6 \%$ \\
\hline Total & 164 & $155,6 \%$ \\
\hline
\end{tabular}

Fuente: Dirección Nacional de Inspección de Trabajo, Departamento de Gestión del MTSS.

Como se observa en la Tabla 1, para el año 2009 las denuncias se triplicaron con respecto a los dos años anteriores, posiblemente por un aspecto de concientización de los afectados que incluso se ve reflejada en el surgimiento de una "Asociación de Víctimas de Acoso Laboral" denominada Asoval, que da apoyo a las víctimas del acoso. Pese a lo indicado, el Máster Erick Briones Briones, abogado del Ministerio de Trabajo y Seguridad Social manifiesta en comunicación personal que la mayoría de las denuncias no son planteadas por temor de la víctima de sufrir más represalias o incluso la pérdida del empleo.

En igual sentido, respecto a la situación en Costa Rica, López (2007) declara: "el acoso laboral o mobbing laboral es muy común en el país, sin embargo representa una cifra negra ya que muchos no denuncian su situación por temor al despido y continúan soportando el maltrato del que son víctimas"
Además del temor al despido, otras limitaciones que podrían estar coadyuvando a que las víctimas no denuncien es la dificultad de obtener las pruebas que sustenten sus afirmaciones. Las pruebas pueden ser documentos, grabaciones, confesiones o bien testigos que puedan servir para demostrar la situación que se pretende probar.

Otro gran problema, es la falta de algún mecanismo de protección judicial que ampare a las personas que sufren acoso laboral (Briones, 2007) y que implique que el empleado no pueda ser despedido mientras se investiga su denuncia.

TABLA 2

\section{Denuncias por hostigamiento en sede Administrativa ante el Ministerio de Trabajo y Seguridad Social Año 2009}

\begin{tabular}{|l|c|c|}
\hline \multicolumn{1}{|c|}{ Hostigamiento laboral } & Absoluto & Porcentual \\
\hline Declarado sin efecto & 40 & $43,50 \%$ \\
\hline No hay dato del resultado & 25 & $27,20 \%$ \\
\hline Se presenta denuncia & 19 & $20,70 \%$ \\
\hline Arreglo entre partes & 6 & $6,50 \%$ \\
\hline NR/ Otros & 2 & $2,10 \%$ \\
\hline Total & 92 & $100,00 \%$ \\
\hline
\end{tabular}

Fuente: Dirección Nacional de Inspección de Trabajo, Departamento de Gestión del MTSS

Como se observa en la Tabla 2, en la vía administrativa, de las 92 denuncias por acoso o hostigamiento laboral, el 29.2\% de los casos el trámite concluyó con la denuncia ante los Tribunales de Justicia. Un 9,2\% llegó a un arreglo, lo cual quiere decir que las partes conciliaron y por tanto el procedimiento terminó.

Dentro de los casos declarados "sin efecto", ante el Ministerio de Trabajo y Seguridad Social, se contabilizan aquellos en los cuales el trabajador renuncia al trabajo o bien es despedido por lo que pierde interés y no continúa con el procedimiento administrativo. 
El acoso laboral, también se presenta en diferentes sectores laborales, pero es principalmente el sector de servicios el que mayoritariamente está acudiendo a interponer las denuncias respecto a este tema (65,2\%). Lo anterior nos lleva a establecer la siguiente relación, digna de mayor profundización: en Costa Rica, en aquellos empleos con mayor nivel de escolaridad, como los del sector servicios se presentan más altos niveles de denuncias por acoso, pero en aquellos en los que se caracterizan por bajos niveles de escolaridad, como lo son el agropecuario y construcción, se presentan cero denuncias por hostigamiento laboral.

TABLA 3

\section{Denuncias por hostigamiento por actividad ante el Ministerio de Trabajo y Seguridad Social Año 2009}

\begin{tabular}{|l|c|c|}
\hline Hostigamiento laboral & Absoluto & Porcentual \\
\hline Agropecuario y extractivas & 0 & $0,0 \%$ \\
\hline Comercio & 24 & $26,1 \%$ \\
\hline Construcción & 0 & $0,0 \%$ \\
\hline Industria & 5 & $5,4 \%$ \\
\hline Servicios & 60 & $65,2 \%$ \\
\hline Transportes & 3 & $3,3 \%$ \\
\hline Total & 92 & $100,0 \%$ \\
\hline
\end{tabular}

Fuente: Dirección Nacional de Inspección de Trabajo, Departamento de Gestión del MTSS.

Otra característica interesante del acoso laboral es que este puede dar inicio como una situación de acoso sexual y posteriormente ante el rechazo que la víctima hace al acosador, se convierta en un problema de acoso laboral, de tal manera que un problema sería consecuencia del otro.

De conformidad con los registros del Ministerio de Trabajo y Seguridad Social, para el año 2009 las denuncias por hostigamiento laboral con relación al hostigamiento sexual son las siguientes:
TABLA 4

\section{Denuncias por hostigamiento laboral y sexual ante el Ministerio de Trabajo y Seguridad Social Año 2009}

\begin{tabular}{|l|c|c|}
\hline \multicolumn{1}{|c|}{ Tipo } & Absoluto & Porcentual \\
\hline $\begin{array}{l}\text { Hostigamiento } \\
\text { laboral }\end{array}$ & 92 & $81,4 \%$ \\
\hline $\begin{array}{l}\text { Hostigamiento } \\
\text { sexual }\end{array}$ & 12 & $10,6 \%$ \\
\hline NR/ Otros & 9 & $8,0 \%$ \\
\hline Total & 113 & $100,0 \%$ \\
\hline
\end{tabular}

Fuente: Dirección Nacional de Inspección de Trabajo, Departamento de Gestión del MTSS.

Finalmente es importante destacar que el acoso sexual en Costa Rica se sanciona mediante una ley especial, lo cual no ocurre con el acoso laboral, como se pasa a explicar.

\section{Normativa costarricense aplicable}

En Costa Rica, no hay normativa específica respecto a la figura del acoso laboral, aunque si ha habido intentos legislativos por regularlo, como ejemplo se puede mencionar el Proyecto de Ley número n. ${ }^{\circ} 16.088$ (Ley para prevenir y sancionar el acoso laboral) que se encuentra en la corriente legislativa. Lo anterior no implica que el trabajador no tenga derecho a su reclamo y correspondiente indemnización (ver al respecto la sentencia 2010-000197 de la Sala Segunda de la Corte Suprema de Justicia).

De tal manera que por no existir una legislación concreta, las denuncias presentadas por acoso laboral se basan principalmente en la Constitución Política, artículo 56, algunos artículos del Código de Trabajo como 19,69, 81, 83, el Código Civil: artículo 1045 y la misma ley General de Administración Pública: 191 y siguientes. Además, se podría recurrir a normativas o reglamentos institucionales, por ejemplo el artículo 108 bis del Estatuto del Personal de la Universidad Estatal a Distancia (UNED). 
A nivel de normativa internacional se puede citar: artículo 14 de la Declaración Universal de los Derechos Humanos, artículos 6 y 11 del Protocolo Adicional de la Convención Americana de Derechos Humanos, artículos 3 y 4 de la Convención Interamericana para la Erradicación de la Violencia contra la Mujer y artículo 5 de la Convención Americana de Derechos Humanos. Esta normativa tutela la imagen, integridad y salud de la persona dentro de un ambiente laboral sano (Briones, 2007).

La vía jurisdiccional para los casos de acoso laboral corresponderá a los procesos ordinarios laborales cuando se soliciten las prestaciones e indemnizaciones previstas en el Código de Trabajo, la otra opción serían los Tribunales Contencioso Administrativos cuando se busque garantizar la legalidad de la función administrativa del Estado, de sus instituciones o de cualquier entidad de derecho público, como por ejemplo anular un acto administrativo que disponga la separación de un funcionario público.

\section{Elementos que caracterizan el acoso laboral en Costa Rica}

La Sala Constitucional de la Corte Suprema de Justicia de Costa Rica ha señalado que los elementos para declarar que ha habido acoso laboral son:

1) Intencionalidad de minar la autoestima $y$ dignidad del funcionario.

2) Repetición de la agresión por un período.

3) Que la agresión provenga de quien tiene la capacidad de causar daño

4) Que la finalidad consiste en presionar al servidor para que abandone su trabajo y así dar por terminada la relación de empleo (Sala Constitucional, 17 de octubre del 2008, entre otros).

Otra resolución que ilustra la tendencia de los órganos jurisdiccionales es la resolución del Tribunal Contencioso Administrativo, Sección IV, del II Circuito Judicial de San José, mediante

\section{FIGURA 3}

\section{Elementos del acoso laboral}

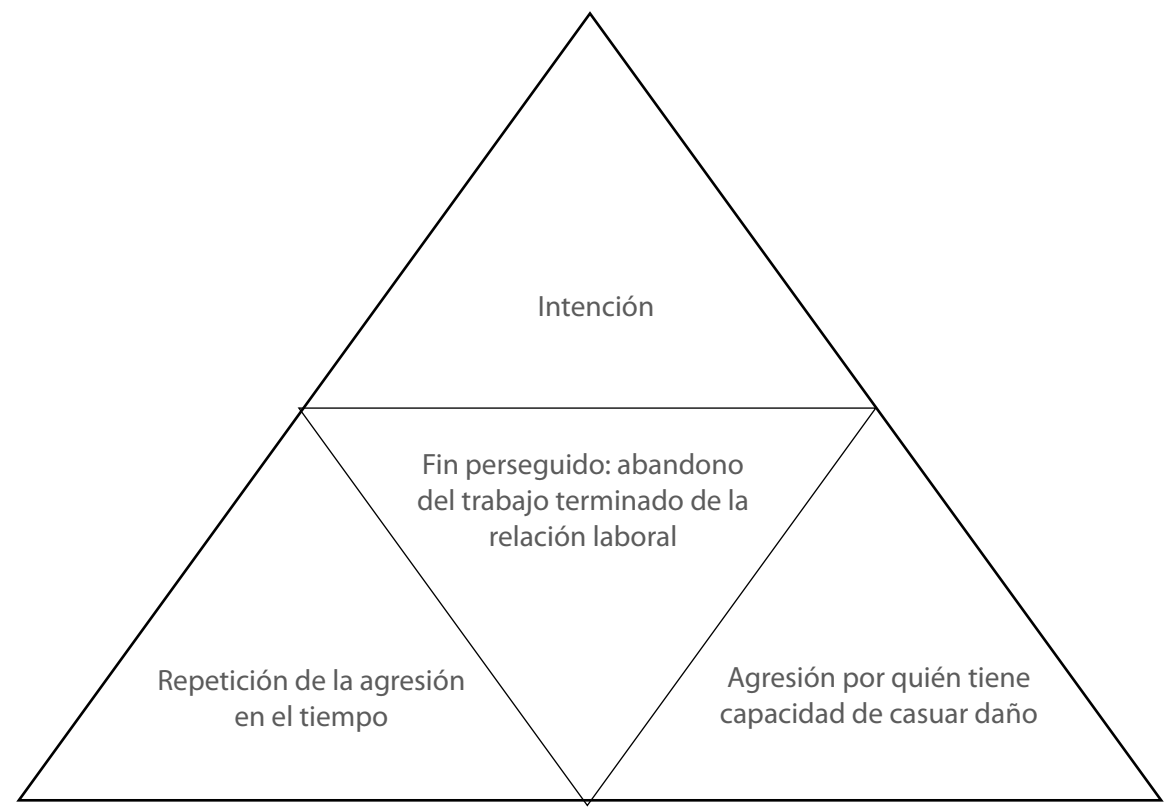

Fuente: Elaboración propia con base en la doctrina y resoluciones judiciales. 
la Resolución N.36 del año 2006, señaló que se requerirían probar cuatro elementos para declarar que ha habido acoso laboral, es decir, los elementos de intencionalidad del agresor, reiteración de la agresión, capacidad del agresor de causar daño y el fin perseguido.

En los casos de acoso laboral, la prueba testimonial, es decir, las manifestaciones de personas cercanas como los compañeros de trabajo de la víctima que hayan visto, oído o de alguna manera percibido la situación vivida por el agredido es fundamental, sin embargo, es justamente el punto complejo de la investigación, ya que es difícil que un compañero de trabajo desee voluntariamente verse involucrado en situaciones laborales conflictivas que no le son propias y que a la postre podría afectarle en su propia situación laboral. De ahí la complejidad de estos procesos para concluir en feliz término para el agraviado.

La carga de la prueba o la responsabilidad de aportar los elementos probatorios los tiene la persona que formula una pretensión o quien se oponga a la misma. De tal manera que el acosado debe demostrar los hechos que denuncia y por los que se considera acosado (art. 317 del Código Procesal Civil).

\section{Descripción de la situación del acoso laboral en Costa Rica}

Con base en la información obtenida vía Internet, en el Sistema Costarricense de Información Judicial, bajo el título de "acoso laboral" al mes de mayo de 2011 se registraron 23 resoluciones judiciales con los siguientes resultados:

\section{Duración}

Las diligencias judiciales relativas al acoso laboral, tuvieron una duración aproximada de uno a seis años (las de un año corresponden a los recursos de amparo interpuestos ante la Sala
Constitucional de Costa Rica, de lo cual se amplía en el punto siguiente). En los juicios ordinarios en sede laboral la duración fue de cuatro a seis años incluyendo la última instancia ante la Sala Segunda de la Corte Suprema de Justicia. Dentro de los 23 juicios, dos se trataron de ordinarios en sede administrativa con una duración de 4 y 5 años aproximadamente (hasta la segunda instancia). Ello quiere decir que la víctima conocerá el resultado de su demanda en promedio cinco años después de interponer la denuncia judicial. Este dato promedio no contabiliza el período que pudo haber durado en el trámite administrativo ante el Ministerio de Trabajo (cuyo trámite es opcional y que puede extender aún más el tiempo para obtener resultados).

\section{Falta de procedimiento especial sancionador}

En Costa Rica no existe un procedimiento especial sancionador, que proteja a las personas que están siendo víctimas de acoso laboral, de tal manera que estas situaciones deben ser planteadas en la vía ordinaria (laboral o contencioso administrativa, según se explicó anteriormente).

De los 23 casos estudiados, catorce correspondieron a Recursos de Amparo presentados ante la Sala Constitucional, recursos que fueron rechazados en cuanto al tema del acoso laboral por indicarse que no era esa la vía correcta para la discusión, ejemplo de ellos las resoluciones 3086 y en igual sentido la 13404, ambas de 2006:

".... En efecto, es criterio de este Tribunal que las acusaciones respecto al supuesto acoso laboral no es una discusión propia de ventilarse ante la jurisdicción constitucional a través de un proceso de amparo, que dada su naturaleza sumaria no permite una discusión plenaria sobre la situación laboral del recurrente...' (Sala Constitucional de la Corte Suprema de Justicia, 10 de marzo de 2006). 


\section{Existencia del acoso laboral}

\section{Abuso del poder jerárquico}

Los tribunales han determinado que sí existe acoso laboral cuando se ha demostrado que ha habido un abuso del poder jerárquico, como en aquellas situaciones en las que el patrono modifica unilateralmente y en perjuicio del trabajador las condiciones esenciales del contrato de trabajo (ej. el salario o la jornada de trabajo, lo que en derecho laboral se conoce como "ius variandi abusivo").

En este sentido se dio un caso de un trabajador que fue trasladado de lugar de trabajo y aunque no se opuso sí solicitó se le brindara tiempo para arreglar sus asuntos familiares como el cambio de escuela de su hijo y el tema habitacional. Al respecto la resolución número 342 de la Sala Segunda indicó:

A la Sala no le cabe la menor duda que el traslado impuesto al trabajador no se ajusta a los aludidos principios de razonabilidad y de buena fe..., no se acreditó la urgencia que tenía la demandada para que éste se realizara ... como tampoco la inexistencia de otra alternativa para proceder como lo hizo. ... De las probanzas se desprende que el actor no se opuso de manera absoluta al traslado, sino, que pidió se tomara en cuenta su situación, incluso ofreció que se llevara a cabo en las vacaciones escolares, lo que denota su buena fe y ánimo de colaboración de su parte... No es posible aceptar que los empleadores dispongan de la fuerza laboral a su antojo, desatendiendo las necesidades personales y familiares del empleado, como si se tratara de un objeto o mercancía, al punto de decirle, como sucedió en el caso de análisis, que ni siquiera le exponga sus problemas (nota de folio 5). Esa actitud patronal, de por sí abusiva, incluso puede ser constitutiva de lo que se ha denominado acoso moral ... Los jueces están obligados a sancionar estas prácticas contrarias a la dig- nidad del ser humano, en procura de mantener ambientes de trabajo libres de violencia ... (Sala Segunda de la Corte Suprema de Justicia, 12 de mayo 2004).

\section{Comportamiento abusivo de los superiores en el trato diario hacia sus subalternos y/o un despido injustificado}

Al respecto hubo un caso de una empleada municipal que cuestionó la legalidad de ciertos actos de su jefatura e inicialmente se negó a ejecutarlos. Por esta razón, la jefatura rompió la cordialidad en las comunicaciones dirigidas a ella y optó por omitir referirse a sus observaciones y girarle órdenes precisas con amenazas solapadas. Además se le trasladó de oficina y se le ubicó en el cementerio de la localidad, sin acondicionarle el local, sin darle mobiliario (el traslado se realizó sin coordinar de con la empleada y sin previo aviso). Se le limitaron las funciones, se le asignaron funciones menos importantes a las que se venían desempeñando, se le variaron las responsabilidades y se le ordenó tramitar los documentos del Cementerio General de Moravia.

La Sala Segunda de la Corte Suprema de Justicia, mediante la resolución 93 del año 2008 resolvió lo siguiente:

... De ahí que no quepa la menor duda de que está en presencia de un típico acoso moral, que hace imperativo declarar la nulidad del despido de la actora. .... En la ejecución de sentencia, el servidor municipal podrá renunciar a ser reinstalado, a cambio de la percepción del importe del preaviso y el auxilio cesantía que puedan corresponderle y el monto dos meses de salario por concepto de daños y perjuicios", se debe otorgar la reinstalación en el puesto ocupado al momento del cese, con el pago de los salarios dejados de percibir desde entonces, incluido el salario escolar. También deben acogerse los reclamos de aguinaldos, anualidades 
acumuladas, aumentos y cualquier otro plus salarial. De conformidad con el último precepto legal citado, la actora podrá renunciar a la reinstalación y optar por el pago de los extremos de preaviso y auxilio de cesantía y, en ese caso, tendrá, además, derecho al monto correspondiente a dos meses de salario por concepto de daños y perjuicios. Sobre las sumas adeudadas se otorgan los intereses legales desde la exigibilidad de cada una y hasta su efectivo pago.... Sobre las sumas a pagar por concepto de salarios, esa debe proceder a rebajar lo correspondiente por cargas sociales y reportarlas como corresponde a la entidad aseguradora (Sala Segunda de la Corte Suprema de justicia, 8 de febrero de 2008).

\section{Indemnizaciones}

Cuando se ha comprobado la existencia del acoso laboral, se ha compensado al trabajador al pago de daños y perjuicios ocasionados, además de todos los derechos correspondientes tales como el preaviso, la cesantía, vacaciones, aguinaldo proporcional, pago de horas extra e intereses, por ejemplo la resolución de la Sala Segunda de la Corte Suprema de Justicia del 12 de mayo del año 2004.

Dentro de los daños indemnizados también se ha contemplado el daño moral, el cual se ha reconocido a los trabajadores que han probado que los actos llevados a cabo por su patrono le han lesionado su honor y su tranquilidad laboral y familiar. Al respecto la resolución 643 de la Sala Segunda de la Corte Suprema de Justicia indicó:

"...Es necesario recordar que el daño moral es una lesión a un derecho extra -patrimonial.... Es innegable que una suspensión irrazonable, en un puesto de la jerarquía del actor genera una grave lesión a su consideración profesional y una perturbación anímica personal y familiar..." (Sala Segunda de la Corte Suprema de Justicia, 10 de febrero 2010).

\section{Inexistencia de acoso laboral}

Los jueces de la República han determinado que no existe acoso laboral, por lo que han declarado sin lugar la demanda interpuesta en situaciones como las siguientes:

\section{Acciones legítimas en función de sus potes- tades de dirección en la organización de su empresa o institución:}

En relación con la actuación del Alcalde Municipal, no encuentra esta Sala que se haya incurrido en lesión alguna a los derechos de petente. Primero porque su actuación lo es en cumplimiento de las funciones inherentes a su puesto de vigilar la organización, el funcionamiento, la coordinación y el fiel cumplimiento de los acuerdos municipales, las leyes y los reglamentos en general, actuación que ejerce ajustada a derecho ya que tal actuación se le notifica efectivamente al petente y se le indican las razones por las cuales opera la medida impuesta... El otro punto, sea la suspensión con goce de salario, tampoco es razón para admitir el reclamo del petente. Ello por cuanto reiteradamente este Tribunal ha indicado que la suspensión con goce de salario con fines precautorios o como medida cautelar a los efectos del procedimiento disciplinario, es procedente y no constituye una lesión a los derechos fundamentales del investigado.... En virtud de lo anterior, el amparo resulta improcedente y así debe declararse... (Sala Constitucional de la Corte Suprema de Justicia, 9 de marzo de 2007).

En el mismo sentido, la Sala Segunda de la Corte Suprema de Justicia en la resolución del 197 de 2010:

...No es posible desconocer que en la vida de relación, patronos y trabajadores se encontrarán enfrascados en muchas situaciones de divergencia de criterio y de imposición legítima de la voluntad patronal respecto del empleado. Se estima legítima porque dentro 
del poder de dirección para llevar adelante su empresa, el patrono tiene la potestad de direccionar los recursos y medios contratados precisamente para la consecución de sus fines lo cual tiene sus límites en el respeto a la dignidad y al ejercicio efectivo de los derechos, por parte de trabajadores y trabajadoras...: (Sala Segunda de la Corte Suprema de Justicia, 10 de febrero de 2010).

\section{Prueba contradictoria}

Se dio el caso de una persona que acude a los Tribunales alegando persecución laboral, pero en el proceso judicial la prueba fue contradictoria ya que los testigos manifestaron que si bien a la actora se le podría haber despedido por sus constantes ausencias e incapacidades, la Jefatura le dio la oportunidad de acogerse a la movilidad laboral. Por lo que se consideró que si no se le otorgaban funciones determinadas en su trabajo, esto se debía a sus constantes incapacidades que la afectaban en el ejercicio del cargo (Tribunal de Trabajo Sección III, Segundo Circuito Judicial de San José, 28 de febrero de 2007).

\section{Incumplimiento de acuerdos}

por parte del trabajador

La resolución de la Sala Segunda de la Corte Suprema de Justicia número 692 expresó que el incumplimiento del trabajador de acuerdos a los que haya llegado con su patrono, le faculta a éste para despedirlo y no constituye un motivo para alegar hostigamiento laboral:

... De la prueba traída al proceso, ha quedado demostrado que en el convenio suscrito por ambas partes en el Ministerio de Trabajo, la actora se obligó a realizar los informes de sus labores y presentárselos día a día a la empresa en el formulario que ésta había confeccionado para ello. Sin embargo, no lo acató de esa manera, contraviniendo las órdenes de sus superiores... De esta prueba se deduce, que lo sucedido no fue hostigamiento, sino un incumplimiento por parte de la actora de lo convenido en el convenio suscrito entre ella y la demandada ante el Ministerio de Trabajo. En consecuencia, con base en lo dicho y en la prueba evacuada, no lleva razón la recurrente, al manifestar que fue objeto de mobbing $u$ hostigamiento laboral por parte de los representantes de la empresa demandada (Sala Segunda de la Corte Suprema de Justicia, 27 de agosto de 2004).

\section{Acciones del supuesto ofendido:}

En uno de los 23 casos en estudio se determinó que no existió acoso laboral cuando el empleado se acogió voluntariamente a la movilidad laboral y no pudo demostrar que fue obligado a ello, tal fue el caso de la resolución del Tribunal, de fecha 19 de abril de 2006:

...En consecuencia, con base en lo dicho anteriormente, y del resto de la prueba evacuada se debe llegar a la conclusión de que no ha existido persecución, maltrato, acoso laboral por parte del banco hacia los actores y todo lo contrario, éstos se valieron del programa de movilidad laboral que programó ese ente, y se beneficiaron de los incentivos de ese plan, y una vez que lograron su objetivo vienen a incoar demanda contra dicho ente, fundándose en hechos que carecen de medios probatorios y que ante esa situación, al ser meros indicios, sin prueba alguna que los respalde.... Se insiste, todo lo contrario quedó demostrado que su voluntad fue libre y sin presión alguna de nadie y que ellos decidieron acogerse al plan de movilidad laboral voluntaria propuesto por el banco, amparado al principio de legalidad con tal actuación" (Tribunal Contencioso Administrativo y Civil de Hacienda, Sección cuarta, Segundo circuito Judicial de San José, 19 de abril de 2006) 


\section{Resultados generales obtenidos}

A través de las resoluciones, se pudo conocer el alto porcentaje de demandas interpuestas y denegadas por haber sido mal planteadas o por no haberse probado los hechos alegados y el bajo porcentaje que se declaró con lugar y se ordenó la indemnización de la víctima por el acoso sufrido (13\% favorables hacia el trabajador) También fue importante conocer los principales argumentos esbozados por los órganos jurisdiccionales en su análisis.

\section{CONCLUSIONES}

Hace aproximadamente 30 años el doctor Heinz Leymann, denomina y sistematiza el estudio del fenómeno denominado "mobbing" o en español acoso laboral u hostigamiento laboral.

En Costa Rica, es hasta hace cuatro años (2007) que se inicia en el Ministerio de Trabajo y Seguridad Social un registro de las denuncias por Hostigamiento Laboral. Ya para el año 2009 se presentaron un total de 92 denuncias por acoso laboral. Dentro de los órganos jurisdiccionales, bajo el tér-

TABLA 5

\section{Resumen de los resultados en las 23 resoluciones relativas al acoso laboral publicadas mediante el Sistema Costarricense de Información}

\begin{tabular}{|c|c|c|c|}
\hline \multicolumn{4}{|c|}{ RECHAZADAS Y OTROS } \\
\hline $\begin{array}{l}\text { ORGANOS } \\
\text { JURISDICCIONALES }\end{array}$ & $\begin{array}{c}\text { NO ES LA } \\
\text { VÍA LEGAL } \\
\text { CORRESPONDIENTE }\end{array}$ & $\begin{array}{c}\text { OTROS (EJEMPLOS: ADMITIDAS EN OTROS TEMAS, } \\
\text { NO ASÍ EN CUANTO AL ACOSO; } \\
\text { SE DEMUESTRAN ACCIONES LEGÍTIMAS } \\
\text { EN FUNCIÓN DE LAS POTESTADES DE } \\
\text { DIRECCIÓN) }\end{array}$ & $\begin{array}{l}\text { CON LUGAR } \\
\text { EN CUANTO AL } \\
\text { ACOSO } \\
\text { LABORAL }\end{array}$ \\
\hline $\begin{array}{l}\text { Sala Constitucional de la } \\
\text { Corte Suprema de Justicia }\end{array}$ & 13 & 1 & \\
\hline $\begin{array}{l}\text { Sala Segunda de la Corte } \\
\text { Suprema de Justicia }\end{array}$ & & 3 & 3 \\
\hline $\begin{array}{l}\text { Tribunal de Trabajo Sección } \\
\text { III, del II Circuito Judicial de } \\
\text { San José }\end{array}$ & & 1 & \\
\hline $\begin{array}{l}\text { Tribunal Contencioso Admi- } \\
\text { nistrativo, Sección VII, del II } \\
\text { Circuito Judicial de San José }\end{array}$ & & 1 & \\
\hline $\begin{array}{l}\text { Tribunal Contencioso Admi- } \\
\text { nistrativo, Sección IV del II } \\
\text { Circuito Judicial de San José }\end{array}$ & & 1 & \\
\hline TOTAL & 13 & 7 & 3 \\
\hline$\%$ & $56,5 \%$ & $30,5 \%$ & $13,5 \%$ \\
\hline
\end{tabular}

Fuente: Elaboración propia con base en las 23 sentencias relativas al acoso laboral obtenidas mediante el Sistema Costarricense de Información Jurídica en mayo de 2011. 
mino "acoso laboral" se localizaron 23 casos cuyas denuncias datan del año 1998 en adelante. De tal manera que éste es un fenómeno relativamente reciente para nuestro país y aunque ya ha habido intentos legislativos, no se ha podido concretar una ley que lo sancione.

Por otra parte, de conformidad con la información obtenida tanto en el Ministerio de Trabajo y Seguridad Social así como en los Órganos Jurisdiccionales, las primeras denuncias sobre estas conductas han sido mayoritariamente infructuosas en el sentido que el denunciante no logra probar sus hechos y no alcanza ser protegido o indemnizado por la situación que alega vivir. Esto es motivo de mucha frustración del afectado al no ver sus derechos resguardados por el sistema.

De los 92 registrados ante el Ministerio de Trabajo y Seguridad Social, solo seis casos (9,2\%) concluyeron con un arreglo entre las partes y solo en 19 de ellas (29,2\%) se indicó que, ante la imposibilidad de una conciliación ante el Ministerio, se continuarían las diligencias en la vía judicial. Dentro de las razones posibles que se señalaron para que la mayoría de las denuncias (aproximadamente un 60\%) no sean llevadas a los tribunales, están la falta de elementos probatorios para sustentar sus dichos, el temor de sufrir más represalias e incluso la pérdida del empleo.

El problema de la falta de elementos probatorios se refleja también en la vía judicial, cuando solo un 23\% de los casos considerados logró probar los hechos y ser indemnizado o reinstalado en sus puestos.

Es importante recordar que como se dijo, en un proceso por acoso laboral, la mejor prueba posiblemente la aportarán los propios compañeros de trabajo de la persona que se dice estar acosada, sin embargo, son las personas menos dispuestas para acudir en defensa de un compañero y poner en riesgo su propia estabilidad laboral.
Un intento legislativo de sancionar el acoso laboral debe contemplar un mecanismo de protección para los denunciantes y sus testigos (compañeros de trabajo) durante el proceso ya sea administrativo o judicial que se lleve a cabo. Es importante la protección a los compañeros de trabajo porque sus testimonios son determinantes por la cercanía con el afectado. Esa protección podría consistir en una imposibilidad temporal de ser despedidos desde que el proceso se inicia y hasta que este concluye.

Otro elemento que constituye una limitación importante es el desconocimiento de los promoventes de la vía correcta para presentar sus peticiones. La Sala Constitucional ha sido reiterativa al indicar que las discusiones relativas a denuncias de acoso laboral deben ser planteadas en la vía ordinaria, esto debido a que los recursos de amparo son de naturaleza sumaria y no para una discusión en pleno de las situaciones investigadas. Es debido a ello que en 13 de los 23 casos (56.5\%) se rechazaron las diligencias por no haberse elegido la vía judicial que correspondía.

Es importante también acotar que claramente los Tribunales han señalado que no hay acoso laboral si un patrono realiza acciones legítimas en función de sus potestades de dirección en la organización de su empresa o institución. Por lo que girar instrucciones y hacerlas cumplir, o hacer cumplir acuerdos que se encuentren en el marco de la legalidad, no constituyen acoso laboral, aun cuando un empleado pueda sentirse amenazado con dichas instrucciones.

Hay que considerar además la necesidad de un procedimiento judicial expedito, que haga honor al principio de justicia pronta y cumplida. Como se pudo constatar, el promedio en juicios ordinarios laborales tuvieron una duración de cinco años (considerando hasta la resolución de la Sala Segunda de la Corte o tercera instancia rogada) 
de tal manera que en el caso de la trabajadora municipal, que fue despedida y presentó la demanda en diciembre del año 2002, es hasta el 8 de febrero del año 2008 que se ordenó la reinstalación al puesto que tenía en el momento del despido, por lo que transcurrieron seis años de disputa legal antes que se le diera la razón de sus argumentos.

Debe además ponerse especial atención en los sectores agropecuario, construcción y transportes, que presentan un bajo porcentaje de denuncias (de 0 a 3\% ante el Ministerio de Trabajo) siendo que se trata de sectores de muy baja escolaridad y que podrían estarse viendo afectados por esa situación. La desinformación puede estar ocasionando situaciones de injusticia que también deben contemplarse.

Según la tipología de acoso laboral que se señaló: ascendente, descendente y entre iguales; los casos estudiados en nuestro país corresponden únicamente a demandas de tipo descendente, lo que quiere decir que se da del superior hacia el subalterno y no viceversa como si se ha presentado en otras latitudes.

Solo en tres casos de los estudiados (correspondiente a un 13\% de las acciones ante Órganos Jurisdiccionales) concluyeron con una sentencia favorable al trabajador por lo que se indemnizó u ordenó la restitución al puesto.

Las empresas e instituciones deben trabajar en procedimientos preventivos del acoso, lo cual evitaría el uso de los medios judiciales que como se ha visto son lentos y muchas veces poco efectivos, pero esto será tema de otro artículo.

\section{REFERENCIAS}

Briones E (2007) Tratamiento del acoso laboral (mobbing) por parte de la Inspección de Trabajo. Ivstitia, No. 21, 20-24.

Costa Rica, Código Procesal Civil, Ley No. 7130, Imprenta Nacional1989

Largaespada, G (2010) Inspección de Trabajo: Casos especiales atendidos en el año 2009" Ministerio de Trabajo y Seguridad Social

López A (2007, junio 20) Acoso laboral desgasta física y emocionalmente a víctimas. La prensa libre tomado de http://www.pren salibre.co.cr/2007/junio/20/abanico08.php

Organización Internacional del Trabajo, Cuando el trabajo resulta peligroso Revista de la OIT, No.26 Descargado el 1 de mayo del 2011 de http://www.ilo.org/public/ spanish/bureau/inf/magazine/26/violence.htm

Pérez, X (2008). Hostigamiento laboral: Mobbing. San José, Universidad de Costa Rica.

Piñuel, I (2001). Mobbing cómo sobrevivir al acoso psicológico en el trabajo. Editorial Sal Terrae

Proyecto de Ley № 16.088 (2006, Mayo 25) La Gaceta número cien.

Romero, J (2006). Mobbing laboral: acoso moral, psicológico [Versión electrónica]. Revista de Ciencias Jurídicas, No. 111, 131- 162, descargado el 15 de mayo 2010 de http://www.iij.derecho.ucr.ac.cr/archivos/documentacion/mobbing.pdf

\section{Jurisprudencia}

Sala Segunda de la Corte Suprema de Justicia, a las 9:50 horas del 10 de febrero de 2010. Expediente 06-300040643-LA. Resolución 2010- 0197. Poder Judicial de la República de Costa Rica. Recuperado el 20 de mayo de 2011 de http://www.pgr.go.cr/SCIJ/.

Sala Constitucional de la Corte Suprema de Justicia, a las 10:03 horas del 13 de enero de 2009. Expediente 0815311-0007-CO. Resolución 2009-00209. Poder Judicial de la República de Costa Rica. Recuperado el 19 de abril de 2010 de http://www.pgr.go.cr/SCIJ/.

Sala Constitucional de la Corte Suprema de Justicia, a las 10:40 horas del 17 de octubre de 2008. Expediente 08009698-0007-CO. Resolución 2008-15592. Poder Judicial de la República de Costa Rica. Recuperado el 19 de abril de 2010 de http://www.pgr.go.cr/SCIJ/. 
Sala Segunda de la Corte Suprema de Justicia, a las 10:20 horas del 8 de febrero de 2008. Expediente 02-3371166-LA. Resolución 2008-00093. Poder Judicial de la República de Costa Rica. Recuperado el 19 de abril de 2010 de http://www.pgr.go.cr/SCIJ/.

Sala Constitucional de la Corte Suprema de Justicia, a las 10:10 horas del 27 de abril de 2007. Expediente 074647-0007-CO Resolución 2007-5786. Poder Judicial de la República de Costa Rica. Recuperado el 19 de abril de 2010 de http://www.pgr.go.cr/SCIJ/

Sala Constitucional de la Corte Suprema de Justicia, a las 10:45 horas del 09 de marzo de 2007. Expediente 070095-007-CO Resolución 2007-3183. Poder Judicial de la República de Costa Rica. Recuperado el 19 de abril de 2010 de http://www.pgr.go.cr/SCIJ/.

Sala Constitucional de la Corte Suprema de Justicia, a las 1:02:00 horas del 09 de marzo de 2007. Expediente 072655-007-CO Resolución 2007-3320. Poder Judicial de la República de Costa Rica. Recuperado el 19 de abril de 2010 de http://www.pgr.go.cr/SCIJ/.

Tribunal Superior de Trabajo, Sección III, a las 8:10 horas del 28 de febrero de 2007. Expediente 04-1910-166-LA, Resolución 2007-86. Poder Judicial de la República de Costa Rica. Recuperado el 19 de abril de 2010 de http://www.pgr.go.cr/SCIJ/.

Sala Constitucional de la Corte Suprema de Justicia a las 3:19 horas del 30 de enero de 2007. Expediente 07000507-007-CO, Resolución 2007-1142. Poder Judicial de la República de Costa Rica. Recuperado el 19 de abril de 2010 de http://www.pgr.go.cr/SCIJ/.

Sala Constitucional de la Corte Suprema de Justicia a las 1:52 horas del 19 de enero de 2007. Expediente 07000514-007-CO, Resolución 2007-00781. Poder Judicial de la República de Costa Rica. Recuperado el 19 de abril de 2010 de http://www.pgr.go.cr/SCIJ/

Sala Constitucional de la Corte Suprema de Justicia a las 2:54 horas del 28 de junio de 2006. Expediente 067180-007- CO, Resolución 2006- 09068. Poder Judicial de la República de Costa Rica. Recuperado el 19 de abril de 2010 de http://www.pgr.go.cr/SCIJ/

Tribunal Contencioso Administrativo, Sección IV a las 10:50 del 19 de abril de 2006. Expediente 02-637-163-CA, Resolución 2006- 0036. Poder Judicial de la República de Costa Rica. Recuperado 19 de abril de 2010 de http://www.pgr.go.cr/SCIJ/
Sala Constitucional de la Corte Suprema de Justicia a las 9:53 horas del 10 de marzo de 2006. Expediente 055113-007-CO, Resolución 2006- 3086. Poder Judicial de la República de Costa Rica. Recuperado. 19 de abril de 2010 de http://www.pgr.go.cr/SCIJ/

Sala Constitucional de la Corte Suprema de Justicia a las 11:26 horas del 30 de setiembre de 2005. Expediente 05- 09487-007-CO, Resolución 2005-13404. Poder Judicial de la República de Costa Rica. Recuperado 19 de abril de 2010 de http://www.pgr.go.cr/SCIJ/

Sala Segunda de la Corte Suprema de Justicia a las 2:05 horas del 3 de agosto de 2005. Expediente 99-001427166- LA, Resolución 2005- 00655. Poder Judicial de la República de Costa Rica. Recuperado 19 de abril de 2010 de http://www.pgr.go.cr/SCIJ/.

Sala Constitucional de la Corte Suprema de Justicia a las 5:12 horas del 24 de mayo de 2005. Expediente 052969- 0007-CO, Resolución 2005-6072. Poder Judicial de la República de Costa Rica. Recuperado 19 de abril de 2010 de http://www.pgr.go.cr/SCIJ/.

Sala Constitucional de la Corte Suprema de Justicia a las 5:56 horas del 25 de enero de 2005. Expediente 0410768-007-CO, Resolución 2005-605. Poder Judicial de la República de Costa Rica. Recuperado 19 de abril de 2010 de http://www.pgr.go.cr/SCIJ/.

Sala Constitucional de la Corte Suprema de Justicia a las 9:16 horas del 24 de setiembre de 2004. Expediente 04- 6576-007-CO, Resolución 2004-10448. Poder Judicial de la República de Costa Rica. Recuperado 19 de abril de 2010 de http://www.pgr.go.cr/SCIJ/.

Sala Segunda de la Corte Suprema de Justicia a las 9:20 horas del 27 de agosto de 2004. Expediente 98-3837166-LA, Resolución 2004- 692. Poder Judicial de la República de Costa Rica. Recuperado 19 de abril de 2010 de http://www.pgr.go.cr/SCIJ/.

Sala Segunda de la Corte Suprema de Justicia a las 8:50 horas del 12 de mayo de 2004. Expediente 02- 217-418LA, Resolución 2004- 342. Poder Judicial de la República de Costa Rica. Recuperado el 19 de abril de 2010 de http://www.pgr.go.cr/SCIJ/.

Sala Segunda de la Corte Suprema de Justicia a las 14:35 horas del 18 de diciembre de 2003. Expediente 02300233-641-LA, Resolución 792-641-la Poder Judicial de la República de Costa Rica. Recuperado el 19 de abril de 2010 de http://www.pgr.go.cr/SCIJ/. 
RNA Revista Nacional de Administración

Tribunal Contencioso Administrativo, Sección VII del Segundo Circuito Judicial de San José a las 15:40 horas de 28 de junio de 2010. Expediente 05- 952- 163-CA, Resolución 63 Poder Judicial de la República de Costa Rica. Recuperado el 20 de mayo de 2011 de http:// www.pgr.go.cr/SClJ/.

Sala Constitucional de la Corte Suprema de Justicia a las 9:02 horas del 7 de mayo de 2010. Expediente 103722-007-co, Resolución 9332. Poder Judicial de la República de Costa Rica. Recuperado el 20 de mayo de 2011 de http://www.pgr.go.cr/SCIJ/.

Recibido: 28 de junio de 2010 Aceptado: 27 de marzo de 2011 